\title{
Some Discussion Based on My School Software Engineering Profession Excellence Program Implementation
}

\author{
Yihe Liu \\ School of Computer Science \\ Neijiang Normal University Neijiang,Sichuan 641100,China \\ e-mail: liu_yihe@163.com
}

\begin{abstract}
The author links to unit's reality, analyzed in my school software engineering profession excellence program implementation to be urgently needed the solution the question. The possibility of the implementation of the order form training mode of the software engineering profession excellence program, and the significance of the implementation of the order training mode are discussed. Talents idea method of implementation and the problem of schools and students should pay attention to so on at order form training mode are studied also in this paper. This is a positive sense for the local high school computer teacher personnel training mode to establish.
\end{abstract}

Keywords- Local teachers colleges; Software Engineering Profession; Excellence Program; Order Form Training Mode; Implementation

\section{INTRODUCTION}

"Excellent engineer education training plan" initiated by the Ministry of Education (the "Excellence") is an important part of the "Long-term Education Reform and Development Plan (2010-2020)", it is designed to train a large number of future engineering innovation capability, adapt to economic and social development, for industry, for the future, the world's outstanding engineering and technical personnel of various types [1]. The software engineering profession of my school was selected in 2013 in Sichuan Province Department of Education Excellence Program, and we began to explore software engineering training mode. This article seeks to objectively my school's Software Engineering Excellence implementation problems were analyzed, discussed. In order to further improve the quality of its personnel training and hope to implement outstanding projects for the Local Normal Universities reference.

Personnel training are the fundamental task of universities. Training based on serving local economies of software engineering profession in higher education from elite education to mass education transformation product, it is the responsibility of the requirements of social economic development, but also local institutions. Graduates of higher education of social development expectations have to be socially acceptable quality and capability [2].

Software engineering applied talents should be based on services for the purpose of employment-oriented, production, construction, management and service of advanced computer applications frontline talents, it is the inevitable product of popularization of higher education, the education and training of localization goals, should be distinguished from academic. "Excellence" focusing on innovation, training of senior engineering and technical personnel, requiring students to master the software engineering disciplines basic theory and engineering technology, basic training in software engineering, basic methods of software technical writing master, pay attention to ethics training, to understand computer software development and project management-related standards, laws, regulations and norms, with sense of integrity and teamwork, with a software project analysis, basic ability to design, construction and organization and implementation, with a good engineering accomplishment, the spirit of innovation and entrepreneurship awareness, the ability to communicate with a preliminary competition and cooperation in certain international perspective and cross-cultural environment [3]. Since 2000, my school to the scientific development concept as a guide to the service area of social and economic development as the main direction in order to cultivate high-quality talents as the goal, to adjust the structure of professional and local economic construction and social development closely, positive declaration of new specialty, expand professional direction, from the previous single Normal computer science and technology professional adjustment normal, non-teacher professional coexist, and to apply the type of professional development based professional structure. 2006 declared successful software engineering, and became the first provincial superior of our school plan professional in 2013. It is more than 900 students, with more than 20 specialized laboratories in my school, with China-soft, Guoxinan, Huadi etc many units have signed a internship training base of agreement, most of the software engineering students on the implementation of excellence initiative is high, practical teaching breakthrough. But it also found that there are some problems in the implementation process, particularly in my school practice, train a number of factors affecting the quality of excellence personnel training process analysis and reflection, personnel training for the implementation of the order based software engineering excellence model discussed to further improve the quality of software engineering excellence in personnel training. 


\section{SOFTWARE ENGINEERING EXCELLENCE PROGRAM IMPLEMENTATION ISSUES NEED TO BE RESOLVED}

\section{A. further update educational idea}

Our university was founded in 2000 upgraded. After 10 years of development, the size of the school is growing rapidly. as the new local universities, our school on the one hand the previous college education problems in the process of running a summary examination; on the other hand on how to run this level of undergraduate education conducted extensive research and reference. However, due to the undergraduate school a short time, undergraduate education and research, lack of run undergraduate education, especially excellent understanding of how to implement the plan. Thus, the original training mode, teaching methods, educational awareness profoundly restrict the ideas administrators and teachers, reflecting the trend of low performance for the idea in the educational process, school awareness not because of school upgraded qualitative change occurs. Under the influence of this concept, professional settings, courses, teaching staff, infrastructure construction of teaching facilities and student management, campus culture construction, according to the old colleges compared to a larger gap.

Software engineering is an application-based profession, you want to run this type of profession should market awareness, faculty, internship training conditions should be different from the traditional education in normal mode, adjust settings based professional and original specialty span, so applied professional educational idea, professional awareness has not yet been fully established, schools tend to "traditional theoretical teaching" of disciplines in educational idea, teaching plan, the education model curriculum and follow the traditional theory of local teachers colleges of undergraduate Education approach.

\section{B. To further improve the structure of the faculty}

The current number of teachers in my school is less than normal, although most teachers also have master's or higher degree, more profound theoretical knowledge of subjects. Although in recent years, we spent a large effort, using various channels to send young teachers to the outside for short-term training, training, but generally speaking, teachers' experience and ability is relatively weak, companies have little experience of teachers,

In the implementation of the "excellence" in the process, teachers need to play a major role in all aspects of education are required to have a more extensive engineering experience. Our teachers are from school to school almost, the lack of practical experience, and it is the key point which is bound by teachers to improve engineering education capacity. Second, the bilingual teaching ability is insufficient, and the "excellent plan" also requests "the world", which must require the teacher to have the big enhancement in the foreign language level. Further, in recent years, colleges and universities in the job classification process, the blind pursuit of scientific research fixed target, ignoring teaching soft targets such young teachers teaching ability, teaching methods, which do not pay attention, not enough to master teaching methods, the lack of teaching experience. Finally, my school is far from chengdu and chongqing city. There is no formation of an effective program for school hiring business engineers as part-time teachers, foreign companies do not want to be engineers, but also the lack of local corporate team of engineers is far an important complement to my school education teachers. Teachers lack the ability to engineering education will be severely stagnant development "excellence" [4].

\section{Pay more attention to the construction of practice training base}

During the culture of excellence engineer, the schoolenterprise cooperation is different from the traditional way of unique culture an important part. Engineering education excellence program is to "return to work" in close cooperation with the companies to implement one of the key " $3+1$ " training mode becomes the engineering education [4-7]. Our school is located in three cities, which is the development of the software industry lags behind, and we can establish school-enterprise cooperation between the very few software companies. In addition, most companies, especially SMEs, the main pursuit of economic interests, due to the lack of supporting national policy, these companies do not take responsibility for the social basic training, and cooperation with large enterprises often need to come forward to solve the school level, thus, leading to carry out the "excellence" serious lack of corporate learning enterprise resources. It has a certain effect on the culture of excellence program personnel.

\section{School policy inflexibility}

For excellence in my school projects, schools although the funds give strong support, but the use of funds subject to many restrictions, resulting in money does not go out, the place and no money to spend, policies that both countries have school leaders thought the reason is not open enough. In addition, the school plans to implement outstanding professional restructuring and other lack of a full range of supporting policies, leading to secondary college, and teachers lack enthusiasm for reform.

\section{SOME DISCUSSION ABOUT SOFTWARE ENGINEERING ORDER TRAINING MODE}

The characteristics of new local teacher universities, combined with my college, following a preliminary study on the mode of software engineering professional order training mode in numerous training mode

\section{A. Order training mode}

Software engineering and local economic ties in recent years, the employment rate of our graduates are more than 95 percent, have a good employment prospects. But how to run a professional, unique, really able to train and adapt to the needs of the local community talent, how to implement good excellent plan, my school has become a serious problem. The implementation of contract training patterns may be one of the effective ways to solve this problem.

1) The possibility of software engineering profession excellence program implementation order training mode

Order training mode is referred to as colleges party and as enterprises employing party, society and the market demand for the jointly developed personnel training programs, employment signed the order, and cooperation 
in teaching, technology, school conditions, by engineering alternating fashion schools and employers respectively, teaching, training model directly to an employer of employment after graduation.

In this mode, we require agreement was clear: the future is designed to train a large number of innovative engineering and strong ability to adapt to economic and social development, for industry, for the future, the world of various types of outstanding engineering and technical personnel, and this and professional excellence aim is to have the software engineering. While clearly schools and employers both sides duties in accordance with the employer to ensure that the needs of schools and training qualified personnel, employers guarantee employment. Order training mode The basic starting point is the school's educational adhere to the employment-oriented social training high quality skilled personnel needed, greatly mobilized schools, employers and the enthusiasm of students in three areas, well-coordinated education, employment and employment in three areas of conflict, to achieve the school, employers and students "win."

This makes software engineering excellence in program implementation may become mode contract training.

2) The significance of software engineering profession excellence program implementation order training mode

Order training is to train for the requirements of employers useful talents, together with employers to develop personnel training programs and institutions, satisfy the actual needs of enterprises jobs for talent, good talent to overcome the shortcomings of traditional training programs to improve the school educational efficiency and student learning. Order training model fundamentally solve the local newly instability brought on by the contradiction of employment, to ensure the stability of teaching management order[8].

Software engineering profession excellence implement personnel training mode orders for local colleges and universities, which ensures personnel training targeted at school, need for employers demand and actual jobs, professional and curriculum adjustment, adjust the teaching content and teaching methods, teaching give students real professional knowledge and skills to ensure students after graduation to full employment. To ensure that students "graduation means employment", in order to protect the fundamental interests of the majority of graduates.

\section{B. The thoughts of software engineering profession excellence program implementation order training mode}

With the rapid socio-economic development and the improvement of people's living standards, the information industry has become one of the most promising industries. Software Engineering Excellence to take orders for training mode, able to adapt to employers choose talent, both diplomas, focusing more on the level of education not only to see more emphasis on the ability to effectively measure this requirement.

\section{1) Solve the problem of non-working faculty}

Features Order Training Mode, requires schools to have a good professional quality "Double" teachers. In the school policy support, "Double Teachers" team building through a variety of channels to resolve. Teachers are encouraged to go to the company testing exercise, assume management project, to participate in the company's operation and management, Cisco Networking Academy College in partnership with Cisco Running, Hua Di, of other companies within the platform, in various forms and means to facilitate the teacher out short-term training, education, business and further improve the teaching level of teachers; the introduction from the community (or hire) the company's professional and technical personnel as a training instructor schools; train college talent through the order cooperative company's technical staff. Software engineering teachers Appointment and assessment will evaluate the project designs, patents, industry cooperation and technical service, priority appointment have to have a certain number of years of work experience in the enterprise of teachers, teacher promotion of business experience.

Promote "multi certificate" education system, namely students in the graduate diploma in addition, the need to obtain the software engineers, network engineers and other professional qualifications. College students are encouraged to participate in various certification exams, students and centralized training, counseling approach to guide students in the research work.

2) To create a good social environment engineering education, use the relationship of stable school-enterprise cooperation to achieve order training mode

Employers are student employment destination, is the order type training model in the "Order" one talent, it must get the support of employers, therefore, the implementation of the first order condition of personnel training, is to have relevant business professionals demand and support, which is the order training mode the essential characteristics of the decision. Establish a stable schoolenterprise cooperation is the basis of successful implementation of the order training.

For software engineering professional of my school, software engineering professional should be demandoriented, reasonable set of professional courses. Through extensive community survey, fully accurate software industry background analysis and research talent supply and demand, so that educational activities be targeted. Courses follow the dynamic and ahead of principle, seize the pulse of the development of information industry, combined with college opened its own school conditions unique, practical courses, to be able to win more share of orders in the job market, but also to and around the various companies to establish good relations of cooperation to ensure the smooth progress of contract training mode.

In order to effectively implement the new mechanism universities and industries and enterprises joint training, the state must put the appropriate policies (administrative or tax policy), to enable enterprises to truly accept the Students practice as their own obligations; to establish universities and enterprises talent flow mechanism between the teachers to go to the corporate office, attachment, part-time teachers to strengthen engineering capabilities. Forming an excellent engineer training of teachers is essential.

3) To achieve orders training model, we clear position in engineering education, and increase 
investment in schools and external training base construction

An order type training model is characterized by significant cooperation by the company or other employer and culture institutions to develop some jobs. Undoubtedly, the employer can not directly recruit recruitment leadership talent, talent can only recruit some practice, but must have certain basic management capabilities. This requires schools and cooperative enterprises to strengthen training base to provide protection for the realization of order training mode.

To this end the government should increase its investment in engineering education, the introduction of evaluation. Check and implementation aspects of school practice conditions necessary for improving the teaching content and quality are important underlying hardware, schools should handle well the relationship between scientific research, subject construction and personnel training between the disciplines in the overall framework, focusing on the construction of a Batch engineering education platform.

4) Deal with the relationship between the three aspects for order training program implementation properly

Orders personnel training is based on the employer under a considerable amount of talent demand, the employer and the college signed a training agreement, according to job requirements should post on the "book" of students to tailor a training model. Orders can only be limited to the part of the personnel training students, but also difficult in all the students. To correctly handle the relationship between contract training and non-contract training between[9-10].

Personnel training in order to work, it should take into account the actual situation of the employer, and not simply to meet the unrealistic demands of employers while ignoring the higher education itself regularity. Deal with the employer, the relationship agreement between the school and the students of orders, the employer (or the agency), schools and students to sign a tripartite agreement for disciplining students and employers, integrity compliance.

\section{SUMMARY}

This article is the summary based on teaching practice experience of the author. The implementation of software engineering profession excellence program and order training mode of my college are discussed preliminarily in this paper. Practice has proved that, in the current poor quality of normal source, the employment pressure, the effect is significant.

\section{ACKNOWLEDGMENT}

Fund Project 1, Sichuan Provincial Education Department in 2013 excellent engineers education and training projects; 2, Sichuan Provincial Education Department in 2015 specializing in transformation projects.

\section{REFERENCE}

[1] Zhang Wensheng, Songke Ru. Implementation of "Excellent engineer education training under the" return to work "philosophy of education thinking plan "[J] Northwestern Polytechnical University, 2011.3: pp77-79

[2] Huangshu Ling. Some thoughts of applied professional training $[\mathrm{DB} / \mathrm{OL}]$

[3] http://www.ahsztc.edu.cn/jxcgj/content/cl4.htm\#08

[4] Lin Jian common standards "Excellent engineer education training program" Development [J] EDUCATION OF ENGINEERING, 2010.4:pp 21-29.

[5] Yu Ying. Li Yun etc.Local universities software Engineering "excellence" strategies [J], the computer age, in 201406.

[6] Wang Hancheng, Jiangyue Jun. On domestic and school-enterprise cooperation mode revelation "Excellence" for China's implementation [J] Huaihai Institute of Technology (Social Sciences), 2010.8: pp14-16.

[7] Ye Jian Ming practice between schools and enterprises to explore the community. [J]. China Higher Education Research, 2009.12.

[8] Wang Tianbao based on innovative CDIO Training Mode Study and Practice [J]. Higher Engineering Education Research, 2010.1.

[9] Ling New Applied Professional Training Mode Reform - hotel management professional "practice, training and employment integration" Training Mode [DB / OL]

[10] http://www.ahsztc.edu.cn/jxcgj/content/cl4.htm\#09

[11] To promote cooperation with enterprises, and take the road [DB / $\mathrm{OL}]$ http://www.xueshuqikan.cn/view.php?cid=151\&tid=22654\&page= 1

[12] Li Jinrong ."Order-Form” Talent Training Model: the Road for College Transformation and Improvement. China Human Resources Development ,2014.23. 